\title{
Effect of Validamycin A on the Production of Cellulase, Xylanase and Polygalacturonase by Rhizoctonia solani
}

\author{
By GEOFFREY D. ROBSON, ${ }^{*}$ PAUL J. KUHN ${ }^{2}$ AND \\ ANTHONY P. J. TRINCI ${ }^{1}$ \\ ${ }^{1}$ Microbiology Group, Department of Cell and Structural Biology, School of Biological Sciences, \\ Stopford Building, University of Manchester, Manchester M13 9PT, UK \\ ${ }^{2}$ Shell Research Limited, Sittingbourne Research Centre, Sittingbourne, Kent ME9 8AG, UK
}

(Received 16 February 1989; revised 5 May 1989; accepted 23 June 1989)

\begin{abstract}
Validamycin A decreased the biomass and extracellular protein produced by cultures of Rhizoctonia solani A79 grown on medium containing cellulose as the carbon source. In the presence of the antibiotic, the production of inducible enzymes active on filter paper (FPase), carboxymethylcellulose (CMCase) and (cellobiase) was decreased, but not the production of constitutive enzymes involved in hemicellulose (xylanase) and pectin (polygalacturonase) degradation. When incorporated in the assay mixtures, validamycin A did not affect the activity of the above enzymes, but the antibiotic did act as a substrate for cellobiase. Validamycin A did not affect the distribution of cellulase enzymes in stationary phase cultures of $R$. solani, and incorporation of inositol in the culture medium did not reverse the effect of the antibiotic on cellulase production. Addition of inositol to the medium decreased the activities of FPase and CMCase in the culture supernatant but had no effect on cellobiase activity. The results are discussed in relation to the way validamycin A controls rice sheath blight.
\end{abstract}

\section{INTRODUCTION}

Validamycin A is an antibiotic used in Japan and elsewhere to control Rhizoctonia solani, the causal agent of rice sheath blight. The antibiotic acts as a paramorphogen, reducing hyphal growth unit length (i.e. increasing branch frequency) without affecting the organism's specific growth rate (Robson et al., 1988, 1989). The stimulatory effect of validamycin A on branching leads, in vitro, to the formation of dense colonies which expand in radius more slowly than untreated colonies (Nioh \& Mizushima, 1974; Trinci, 1985; Robson et al., 1988, 1989). The effect of validamycin on the morphology of mycelia of $R$. solani has been correlated with a decrease in the phosphatidylinositol content of the biomass (Robson et al., 1989). Although neither fungicidal nor fungistatic, validamycin is able to control rice sheath blight by reducing the rate of spread of the pathogen from the lower to the upper regions of rice plants. In addition, the antibiotic reduces 'cushion' development and the rate of formation and development of fungal lesions (Wakae \& Matsuura, 1975). Anatomical studies of plant tissue at the boundaries of fungal lesions revealed that, compared with lesions developed on untreated plants, validamycin A reduced the disintegration of parenchyma tissue (Endo \& Wakae, 1983; Endo et al., 1983), suggesting that the antibiotic might affect the production of extracellular enzymes (cellulase and pectinase) involved in tissue maceration. Although a previous in vitro study failed to demonstrate an effect of validamycin A on the production or activity of cellulase (Endo et al., 1983 ), the antibiotic is known to inhibit the production by $R$. solani of $\beta$-1,3-glucan synthase, $\beta$ glucosidase and laminarinase (Uyeda et al., 1985, 1986). Another paramorphogen, L-sorbose,

Abbreviations: CMCase, carboxymethylcellulase; FPase, enzyme with activity against filter paper; PGase, polygalacturonase. 
has been shown to affect the production of $\beta$-glucosidase and cellulase by Trichoderma reese $i$ (Bisaria et al., 1986; Sahoo et al., 1986; Nanda et al., 1986). The purpose of the present study was to investigate the effects of validamycin A on the production of extracellular enzymes by $R$. solani.

\section{METHODS}

Organism and media. Rhizoctonia solani A79 was obtained from Dr A. Goulds, University of Manchester, and was maintained at $4{ }^{\circ} \mathrm{C}$ on malt extract agar (Lab M) slopes under paraffin oil. $R$. solani was grown at $25^{\circ} \mathrm{C}$ in shake flask [ $250 \mathrm{ml}$ conical flasks containing $50 \mathrm{ml}$ volumes of Vogel's (1956) medium shaken at 200 r.p.m.] liquid culture with sixteen $1 \times 1 \mathrm{~cm}$ squares of cellulose filter paper (Whatman no. 1) as the sole carbon source in each flask. Flasks were inoculated with $2 \mathrm{ml}$ volumes of a mycelial macerate prepared by homogenizing $R$. solani biomass in distilled water. The resultant macerate was filtered through two layers of muslin and the suspension adjusted with water to give an optical density of 1.0 at $540 \mathrm{~nm}$.

Enzyme preparation. Mycelia and undegraded cellulose were collected from cultures using a single layer of muslin and washed with $50 \mathrm{ml}$ distilled water. The washed biomass was suspended in $20 \mathrm{ml}$ ice cold buffer $(0.1 \mathrm{M}$ citrate/phosphate buffer, $\mathrm{pH} 5$ ) and homogenized for $30 \mathrm{~s}$ at high speed (MSE homogenizer). The resulting homogenate was sonicated (100 W, MSE M284 ultrasonic disintegrator) in an ice bath for periods of $30 \mathrm{~s}$ with $60 \mathrm{~s}$ gaps between successive sonications to avoid overheating the sample. The amount of protein released after each sonication was measured using the Bradford reagent (Bradford, 1976) and six successive cycles of sonication was found to give maximal protein release from the biomass (results not shown). The homogenate was centrifuged at $4{ }^{\circ} \mathrm{C}$ for $40 \mathrm{~min}$ at $13000 \mathrm{~g}$ and the supernatant (the soluble fraction) collected. This fraction was examined at a magnification of $\times 400$ by light microscopy to verify that it was free of cell debris. The pellet was washed twice by suspending it in $20 \mathrm{ml}$ ice cold buffer followed by centrifugation. Finally the pellet was suspended in $20 \mathrm{ml}$ cold buffer (the insoluble fraction).

Biomass determinations. Due to the presence of undegraded substrate (cellulose), chitin was used as an indicator of fungal biomass (Ride \& Drysdale, 1972).

Enzyme assays. Filter paper (FPase), carboxymethylcellulase (CMCase), xylanase and cellobiase activities were determined as described by Lowe et al. (1987). The reaction mixture was incubated at $40^{\circ} \mathrm{C}$ and $\mathrm{pH} 5$ to measure FPase activity, $50^{\circ} \mathrm{C}$ and $\mathrm{pH} 5$ to measure xylanase activity, $55^{\circ} \mathrm{C}$ and $\mathrm{pH} 5$ to measure cellobiase activity and $55^{\circ} \mathrm{C}$ and $\mathrm{pH} 4$ to measure CMCase activity. Polygalacturonase (PGase) activity was determined by incubating a $0.25 \mathrm{ml}$ sample with $0.5 \mathrm{ml} 0.1 \mathrm{M}$-citrate/phosphate buffer $(\mathrm{pH} 5)$ and $0.25 \mathrm{ml}$ of a suspension $\left(20 \mathrm{mg} \mathrm{ml}^{-1}\right)$ of polygalacturonic acid (Sigma) at $50^{\circ} \mathrm{C}$ for $60 \mathrm{~min}$ in a reciprocal shaking water bath (150 strokes $\left.\mathrm{min}^{-1}\right)$. The reaction was terminated by the addition of $2 \mathrm{ml}$ modified dinitrosalicylic acid reagent and the reducing sugar was determined (Lowe et al., 1987) after removal of undegraded polygalacturonic acid by centrifugation (MSE Microcentaur, high speed, $2 \mathrm{~min}$ ). Enzyme activities are expressed as nkat ( $\mathrm{ml}$ culture supernatant) ${ }^{-1}, \mathrm{nkat}$ (mg culture supernatant $)^{-1}$, nkat (mg dry weight of biomass) $)^{-1}$ or total nkat (katal = amount of enzyme activity that transforms $1 \mathrm{~mol}$ substrate $\mathrm{s}^{-1}$ ).

Effect of validamycin and cellubiose on enzyme activity. To determine the effects of validamycin A and cellobiose on enzyme activity, enzyme assays were performed in the presence of either $100 \mu \mathrm{M}$-validamycin A or cellobiose.

Temperature and pH optima of the enzymes. Enzyme activities were measured in the culture supernatant at pH 5 as a function of temperature over the range $20-60^{\circ} \mathrm{C}$ for incubation times of 20-120 min. Enzyme activities were also measured at the optimum temperature over the $\mathrm{pH}$ range $2-9$ in increments of $0.5 \mathrm{pH}$ unit (in $0.1 \mathrm{M}$ citrate/phosphate buffer).

\section{RESULTS}

Temperature and pH optima of enzyme activities in the culture supernatant

The $\mathrm{pH}$ and temperature optima of the enzyme activities in the supernatant of stationary phase cultures of $R$. solani grown on medium containing filter paper as the carbon source were: FPase, pH 4.5-5.5, $40{ }^{\circ} \mathrm{C}$; CMCase, $\mathrm{pH} 4,55^{\circ} \mathrm{C}$; cellobiase, $\mathrm{pH} \mathrm{5,} 50{ }^{\circ} \mathrm{C}$; xylanase, $\mathrm{pH} 5$, $50{ }^{\circ} \mathrm{C}$; PGase, $\mathrm{pH} 5-5 \cdot 5,50^{\circ} \mathrm{C}$.

\section{Effect of validamycin A on biomass, extracellular protein production and enzyme production}

Validamycin $A$ at a concentration of $1 \mu \mathrm{M}$ caused a significant $(P<0.05)$ reduction in the biomass of cultures of $R$. solani grown on filter paper (Table 1), but no further decrease in biomass was observed when the concentration of validamycin $A$ in the medium was increased to $100 \mu \mathrm{M}$. Validamycin A also caused a significant $(P<0.05)$ decrease in the amount of 
Table 1. Effect of validamycin A on biomass concentration, extracellular protein concentration and $\mathrm{pH}$ of cultures of $\mathrm{R}$. solani $A 79$

$R$. solani A79 was grown at $25^{\circ} \mathrm{C}$ in shake flask culture in Vogel's medium containing filter paper as sole carbon source and in the presence of $0,1,25$ or $100 \mu \mathrm{M}$-validamycin A. After $6 \mathrm{~d}$, the biomass, extracellular protein and $\mathrm{pH}$ of the cultures were determined. Results represent the means of five replicate flasks $\pm \mathrm{SE}$.

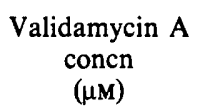

$\begin{array}{rl}0 & 61 \cdot 7 \pm 5 \cdot 8 \\ 1 & 40.0 \pm 2.5 \ddagger \\ 25 & 38.4 \pm 6 \cdot 2 \ddagger \\ 100 & 39 \cdot 1 \pm 4.0 \ddagger\end{array}$

$$
\begin{gathered}
\begin{array}{c}
\text { Estimated } \\
\text { biomass per } \\
\text { flask (mg)* }
\end{array} \\
61 \cdot 7 \pm 5 \cdot 8 \\
40.0 \pm 2.5 \ddagger \\
38.4 \pm 6.2 \ddagger \\
39 \cdot 1 \pm 4.0 \ddagger
\end{gathered}
$$

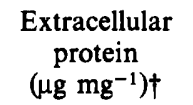

$$
\begin{array}{r}
16.5 \pm 1.3 \\
14.9 \pm 2.3 \ddagger \\
11.2 \pm 2.0 \ddagger \\
2.9 \pm 1.4 \ddagger
\end{array}
$$

$\begin{gathered}\text { Final pH } \\ \text { of culture } \\ \text { supernatant }\end{gathered}$
$6.30 \pm 0.02$
$6.24 \pm 0.03$
$6.43 \pm 0.11$
$6.10 \pm 0.04$

* Chitin was used to estimate biomass and the results are expressed as mg mycelial dry weight. $\dagger$ Results are expressed as $\mu \mathrm{g}$ protein (mg dry weight mycelium) ${ }^{-1}$.

$\ddagger$ Significantly (using the $t$-test, $P<0.05$ ) different from the control lacking validamycin $\mathrm{A}$.

\section{Table 2. Effect of validamycin $A$ on the production of some extracellular enzymes of R. solani $A 79$}

$R$. solani was grown at $25^{\circ} \mathrm{C}$ in shake flask culture in Vogel's medium containing filter paper as sole carbon source and in the presence of 1,25 or $100 \mu \mathrm{M}$-validamycin A. After $6 \mathrm{~d}$, enzyme activities in the culture supernatants were determined. Each enzyme assay was performed in triplicate and the results represent the means of five replicate flasks \pm SE. Dry weight was estimated from measurements of chitin content (see Methods).

\begin{tabular}{lcccc} 
& \multicolumn{4}{c}{ Enzyme activity [nkat (mg dry wt) ${ }^{-1}$ ] } \\
\cline { 2 - 5 } Enzyme & 0 & \multicolumn{4}{c}{ Validamycin A concn in medium $(\mu \mathrm{M}):$} \\
FPase & $0.13 \pm 0.01$ & $0.03 \pm<0.01^{*}$ & $0.03 \pm<0.01^{*}$ & $0.02 \pm<0.01^{*}$ \\
CMCase & $1.13 \pm 0.12$ & $0.03 \pm<0.01^{*}$ & $0.11 \pm<0.05^{*}$ & $0.02 \pm<0.01^{*}$ \\
Cellobiase & $0.83 \pm 0.04$ & $0.22 \pm 0.02^{*}$ & $0.17 \pm<0.08^{*}$ & $0.12 \pm 0.02^{*}$ \\
Xylanase & $6.35 \pm 0.12$ & $6.69 \pm 0.39$ & $6.57 \pm 0.37$ & $6.97 \pm 0.37$ \\
PGase & $0.39 \pm 0.03$ & $0.30 \pm 0.03$ & $0.27 \pm 0.04$ & $0.29 \pm 0.03$
\end{tabular}

* Significantly (using the $t$-test, $P<0.05$ ) different from control lacking validamycin $A$.

extracellular protein produced per mg of biomass; reductions in extracellular protein of $10 \%$, $32 \%$ and $82 \%$ were observed in the presence of 1,25 and $100 \mu \mathrm{M}$-validamycin A respectively. However, no significant difference $(P>0.05)$ was found in the $\mathrm{pH}$ of the supernatants of cultures grown in the presence and absence of validamycin $A$.

Table 2 shows the effect of validamycin A on the activity of several extracellular enzymes in the supernatant of stationary phase cultures of $R$. solani; $1 \mu \mathrm{M}$-validamycin A caused significant $(P<0.05)$ reductions in the extracellular activities of FPase $($ a $77 \%$ reduction compared with the control), CMCase ( $97 \%$ reduction) and cellobiase ( $73 \%$ reduction), but had no significant $(P>0.05)$ effect on the xylanase or PGase activities of the culture supernatants. No further reduction in FPase or CMCase activity was observed when the validamycin A concentration was increased to $100 \mu \mathrm{M}$, but a further significant $(P<0.05)$ decrease in cellobiase activity occurred at a validamycin concentration of $100 \mu \mathrm{M}$.

In order to investigate the effect of the antibiotic on the distribution of enzymes in cultures of $R$. solani, mycelia were fractionated into insoluble and soluble fractions and the activities of each enzyme in the various fractions were determined. Table 3 shows the enzyme activities in the three fractions after $6 \mathrm{~d}$ growth of $R$. solani (stationary phase) in the presence and absence of 
Table 3. Effect of validamycin $A$ on the total activity and distribution of some enzymes produced by $R$. solani $A 79$

$R$. solani was grown at $25^{\circ} \mathrm{C}$ in shake flask culture in Vogel's medium containing filter paper as sole carbon source and in the presence and absence of $25 \mu \mathrm{M}$-validamycin A. After $6 \mathrm{~d}$, mycelium and culture filtrate were harvested and the mycelium fractionated into soluble and insoluble fractions (see Methods). The enzyme activities in each of the three fractions were determined. Results are expressed as nkat (estimated mg dry weight mycelium) ${ }^{-1}$. Each enzyme assay was performed in triplicate and the results represent the means of three replicate flasks. Dry weight was estimated from measurements of chitin content (see Methods).

\begin{tabular}{|c|c|c|c|c|c|}
\hline \multirow[b]{2}{*}{ Enzyme } & \multirow[b]{2}{*}{$\begin{array}{c}\text { Validamycin A } \\
\text { concn } \\
(\mu \mathrm{M})\end{array}$} & \multicolumn{4}{|c|}{ Enzyme activity [nkat (mg dry wt $)^{-1}$ ] } \\
\hline & & Total* & $\begin{array}{c}\text { In } \\
\text { culture } \\
\text { supernatant }\end{array}$ & $\begin{array}{l}\text { In soluble } \\
\text { fraction of } \\
\text { biomass }\end{array}$ & $\begin{array}{c}\text { In insoluble } \\
\text { fraction of } \\
\text { biomass }\end{array}$ \\
\hline FPase & $\begin{array}{r}0 \\
25\end{array}$ & $\begin{array}{l}0.27 \\
0.08+\end{array}$ & $\begin{array}{l}0.13 \\
0.03 \dagger\end{array}$ & $\begin{array}{l}0.02 \\
0.00 \dagger\end{array}$ & $\begin{array}{l}0.12 \\
0.05 \dagger\end{array}$ \\
\hline CMCase & $\begin{array}{r}0 \\
25\end{array}$ & $\begin{array}{l}2.04 \\
0.33 \dagger\end{array}$ & $\begin{array}{l}1 \cdot 13 \\
0.11 \dagger\end{array}$ & $\begin{array}{l}0.18 \\
0.00 \dagger\end{array}$ & $\begin{array}{l}0.73 \\
0.22+\end{array}$ \\
\hline Cellobiase & $\begin{array}{r}0 \\
25\end{array}$ & $\begin{array}{l}3.27 \\
1.36 \dagger\end{array}$ & $\begin{array}{l}0.83 \\
0.17 \dagger\end{array}$ & $\begin{array}{l}0.07 \\
0.01 \dagger\end{array}$ & $\begin{array}{l}2 \cdot 37 \\
1 \cdot 18+\end{array}$ \\
\hline Xylanase & $\begin{array}{r}0 \\
25\end{array}$ & $\begin{array}{l}7 \cdot 38 \\
7 \cdot 32\end{array}$ & $\begin{array}{l}6 \cdot 35 \\
6.57\end{array}$ & $\begin{array}{l}0 \cdot 16 \\
0 \cdot 00\end{array}$ & $\begin{array}{l}0.87 \\
0.75\end{array}$ \\
\hline PGase & $\begin{array}{r}0 \\
25\end{array}$ & $\begin{array}{l}0.40 \\
0.37\end{array}$ & $\begin{array}{l}0.39 \\
0.37\end{array}$ & $\begin{array}{l}0.01 \\
0.00\end{array}$ & $\begin{array}{l}0.00 \\
0.00\end{array}$ \\
\hline
\end{tabular}

* Sum total of the three fractions.

† Significantly (using the $t$-test, $P<0.05$ ) different from control lacking validamycin A.

$25 \mu \mathrm{M}$-validamycin A. In both the control and validamycin A treated cultures, approximately $50 \%$ of the FPase activity was found in the culture supernatant and $50 \%$ in the insoluble fraction of the biomass. The FPase activity in each fraction was reduced by the antibiotic and the total FPase activity was decreased by about $70 \%$ (from 0.27 to 0.08 nkat mg ${ }^{-1}$ ). Approximately half $(53 \%)$ of the CMCase activity was found in the culture supernatant with the remaining activity occurring in the insoluble $(36 \%)$ and soluble $(9 \%)$ fractions. Validamycin A reduced the CMCase activity in each fraction but had a greater effect on the extracellular activity than on activities in the soluble and insoluble fractions. Overall, CMCase activity was reduced by $84 \%$ (from 2.04 to 0.33 nkat $\mathrm{mg}^{-1}$ ).

Most of the cellobiase activity, unlike that of the other enzymes, was found in the insoluble fraction $(72 \%)$ with the remainder in the culture supernatant $(28 \%)$. Again, the activity in both fractions was reduced in the presence of the antibiotic, but, as with CMCase, the activity of the culture supernatant was affected more than that of the insoluble fraction. Overall, cellobiase activity was reduced by $58 \%$ (from 3.27 to 1.36 nkat $\mathrm{mg}^{-1}$ ).

Xylanase activity was restricted largely to the culture supernatant $(86 \%)$ with the remainder being present in the insoluble fraction (14\%). PGase activity was found only in the culture supernatant. Validamycin A had no significant $(P>0.05)$ effect on either xylanase or PGase activity, and had no appreciable effect on the distribution of either enzyme.

Validamycin A (up to $100 \mu \mathrm{M}$ ) had no effect on the activity of any of the enzymes when added to the assay systems, although the antibiotic was found to be a substrate for cellobiase (results not shown). Validamycin A contains a $\beta$-1,4-linked glucose residue which appears to be important for antibiotic activity (Wakae \& Matsuura, 1975). In order to investigate the possible role of this linkage group in the effect of the antibiotic on enzyme production, the effect of cellobiose (a $\beta$-1,4-disaccharide) on enzyme production was studied. The presence of $100 \mu \mathrm{M}-$ cellobiose in the medium had no significant $(P>0.05)$ effect on the production of extracellular activity of any of the enzymes tested (results not shown). 
Table 4. Effect of inositol on the production of extracellular FPase, CMCase and cellobiase by $R$. solani $A 79$ grown in the presence and absence of validamycin $A$

$R$. solani A79 was grown at $25^{\circ} \mathrm{C}$ in shake flask culture in Vogel's medium containing filter paper as carbon source and in the presence and absence of validamycin $\mathrm{A}$ and inositol. Culture supernatants were harvested after $6 \mathrm{~d}$ and the enzyme activities determined. Each enzyme assay was performed in triplicate and results represent the means of five replicate flasks $\pm \mathrm{SE}$.

\begin{tabular}{lccccc} 
& \multicolumn{4}{c}{$\begin{array}{c}\text { Validamycin } \mathrm{A} \\
\text { concn } \\
\text { Enzyme }\end{array}$} & $\overbrace{\text { Inositol concn in medium }(\mathrm{mM})}^{\text {Enzyme activity in culture supernatant (nkat } \mathrm{ml}^{-1} \text { ) }}$ \\
FPase & 0 & 0 & 0.1 & 1.0 & 5.0 \\
& 1 & $0.12 \pm 0.01 \dagger$ & $0.07 \pm<0.01^{*}$ & $0.05 \pm<0.01^{*}$ & $0.04 \pm<0.01^{*}$ \\
CMCase & 0 & $1.35 \pm 0.08 \dagger$ & $0.95 \pm 0.04^{*} \dagger$ & $0.48 \pm 0.04^{*} \dagger$ & $0.16 \pm 0.02^{*} \dagger$ \\
& 1 & $0.39 \pm 0.05^{*}$ & $0.28 \pm 0.01^{*} \dagger$ & $0.26 \pm 0.01^{*} \dagger$ & $0.23 \pm 0.01^{*} \dagger$ \\
Cellobiase & 0 & $0.67 \pm 0.03 \dagger$ & $0.52 \pm 0.06 \dagger$ & $0.51 \pm 0.01 \dagger$ & $0.59 \pm 0.04^{*}$ \\
& 1 & $0.30 \pm 0.02^{*}$ & $0.31 \pm 0.01$ & $0.28 \pm 0.03$ & $0.34 \pm 0.06$
\end{tabular}

* Significantly (using the $t$-test, $P<0.05$ ) different from control lacking validamycin $A$ and inositol. $\dagger$ Significantly $(P<0.05)$ different from control containing validamycin A but lacking inositol.

\section{Interaction of inositol and validamycin $A$}

Since it has been shown (Robson et al., 1989) that the effect of validamycin A on the morphology of $R$. cerealis is correlated with a reduction in the phosphatidylinositol content of the biomass, experiments were made to determine if addition of inositol to the medium would reverse the effect of the antibiotic on enzyme production. A further reason for doing this experiment was that it has been shown that inositol antagonizes the effect of validamycin $A$ in controlling rice sheath blight (Wakae \& Matsuura, 1975).

Table 4 shows the interaction between inositol and validamycin $A$ on enzyme activities in the supernatant cultures of $R$. solani. The presence of $0 \cdot 1,1$ or $5 \mathrm{~mm}$-inositol caused a significant $(P<0.05)$ decrease in FPase activity in the absence of validamycin A, but had no significant effect in its presence. Inositol caused a significant $(P<0.05)$ decrease in CMCase activity in both the presence and absence of validamycin A. The CMCase activity in the absence of the antibiotic was significantly $(P<0.05)$ reduced when the inositol concentration was increased from 0.1 to $5 \mathrm{~mm}$. However, no further reduction in activity was found in the presence of validamycin $A$ when the inositol concentration in the medium was increased above $0.1 \mathrm{mM}$ (Table 4). The presence of inositol, even up to a concentration of $5 \mathrm{~mm}$, had no significant $(P>0.05)$ effect on cellobiase activity in either the presence or absence of validamycin $A$.

\section{DISCUSSION}

The production of xylanase by $R$. solani grown on cellulose (Tables 2 and 3 ) may be due either to the inducers present in filter paper (Lynch et al., 1981) or, as seems more likely, to the constitutive nature of the enzyme. PGase is also a constitutive enzyme and was produced when $R$. solani was grown on glucose (results not shown), as well as when it was grown on cellulose (Tables 2 and 3). Thus, the results in Tables 2 and 3 show that validamycin A reduces the production of the inducible enzymes examined (FPase, CMCase and cellobiase) but not of the constitutive enzymes (xylanase and PGase) involved in the maceration of plant tissue. Further, Table 3 shows that the reduced activities of FPase, CMCase and cellobiase in the culture supernatant were not simply the result of a change in the distribution of these enzymes in the biomass. Thus, as the antibiotic had no direct effect on enzyme activity, the results suggest that validamycin $A$ inhibits the production of the cellulase complex. By contrast, L-sorbose (another paramorphogen) has been shown to increase the extracellular activity of $\beta$-glucosidase (Bisaria et al., 1986; Sahoo et al., 1986) and endoglucanase (Sahoo et al., 1986; Nanda et al., 1986) in Trichoderma reesei. The overall $\beta$-glucosidase activity was unchanged by L-sorbose, the increase 
in extracellular activity being correlated with a decreased activity of wall bound enzyme. The increased activity of endoglucanase in $T$. reese $i$ has been correlated with the increased number of hyphal tips present in L-sorbose treated cultures (it has been suggested that cellulase is secreted from hyphal tips; Bisaria et al., 1986).

The decreased production of the cellulase complex caused by validamycin A does not appear to be due to the $\beta-1,4$-glycosidic linkage between the glucose and validoxylamine $A$ residue nor to its utilization as a carbon source, as addition of up to $100 \mu \mathrm{M}$ of the disaccharide $(\beta-1,4$ linked glucose residues) cellobiose to the medium had no significant effect on the production of the extracellular enzymes by cultures grown on filter paper.

The inhibitory effect of $1 \mu \mathrm{M}$-validamycin A on FPase, CMCase and cellobiase production, the restriction of the effect of the antibiotic to the production of the cellulase complex, and the reported inability of validamycin $A$ to reduce the overall production of constitutive $\beta$ glucosidase (Uyeda et al., 1986), suggest that the antibiotic may interfere with the induction of the cellulase complex. Cellulase enzymes are repressed during growth on readily utilized carbon sources (e.g. glucose) and are induced during growth on cellulose, cellobiose (Mandels \& Reese, 1960) or derivatives of cellulose such as carboxymethylcellulose (Willick et al., 1984). The induction of cellulase enzymes by insoluble cellulose has led to the hypothesis that low constitutive levels of cellulase may release small molecular mass products which either act as, or become converted to, an inducer (Mandels \& Reese, 1960; Mandels et al., 1962). Cellobiose can induce cellulase production in many fungi and the disaccharide sophorose has been shown to act as a powerful inducer of cellulase production, although only in T. reesei (Steinberg \& Mandels, 1979). Sophorose is generated by the action of $\beta$-glucosidase on the products of cellulose breakdown by a transglycosylation reaction (Vaheri et al., 1979). Inactivation of the surface bound $\beta$-glucosidase by the inhibitors nojirimycin or glucono- $\delta$-lactone has been shown to prevent cellulase induction by cellulose, but not by sophorose (Kubicek, 1987). Cellulase induction in $T$, reesei is considered to involve the initial action of low levels of constitutive endoglucanase with the subsequent formation of an inducer (sophorose) from the products of cellulose hydrolysis by $\beta$-glucosidase via a transglycosylation reaction. A similar system of inducer formation may well operate in other cellulolytic fungi. The discovery that various transglycosylation products, including both di- and trisaccharides containing $\beta-1,6-, \beta-1,4-$ and $\beta$-1,2-glycosidic linkages, are formed by endoglucanase and $\beta$-glucosidase (Okada $\&$ Nisizawa, 1979; Gritzali \& Brown, 1979), has led to speculation that, like sophorose in $T$. reesei, other cellulase inducers may be formed by transglycosylation reactions. As validamycin $\mathrm{A}$ is a substrate for $\beta$-glucosidase (Asano et al., 1987), the presence of the antibiotic could compete with the natural substrate, reducing the formation of inducer, and hence cellulase production. Alternatively, validamycin A may compete with the inducer, but not cause induction of cellulase.

If validamycin A causes a decrease in the production of the cellulase complex in vivo, it would explain both the decreased ability of the pathogen to penetrate host tissue (Wakae \& Matsuura, 1975) and the observed reduction in tissue degeneration (Endo et al., 1983) when infected plants are treated with the antibiotic. However, antagonism of the protective effects of validamycin A by inositol (Wakae \& Matsuura, 1975) does not appear to result from a reversal of cellulase inhibition (Table 4). The decreased production of cellulase caused by inositol was presumably due to its utilization as a carbon source for growth (Merivouri et al., 1984).

We thank the Science and Engineering Research Council for a CASE Studentship to the University of Manchester and Shell Research Ltd, Sittingbourne.

\section{REFERENCES}

Asano, N., Yamaguchi, T., Kameda, Y. \& Matsui, $K$. (1987). Effect of validamycins on glycohydrolases of Rhizoctonia solani. Journal of Antibiotics 40, 526-532.

Bisaria, V. S., Nanda, M. \& Ghose, T. K. (1986). Effect of $L$-sorbose on release of $\beta$-glucosidase by Trichoderma reesei QM9414. Journal of General Microbiology 132, 973-978.
BradFord, M. M. (1976). A rapid and sensitive method for the quantitation of microgram quantities of protein utilising the principle of protein-dye binding. Analytical Biochemistry 72, 248-254.

ENDO, T. \& WAKAE, O. (1983). Relation between fine spots on broad bean leaf inoculated with Rhizoctonia solani and degradation of the leaf's glandular hair- 
tissues. Transactions of the Mycological Society of Japan 24, 165-172.

Endo, T., Matsuura, K. \& Wakae, O. (1983). Effect of validamycin A on infection of Rhizoctonia solani in rice sheaths. Annals of the Phytopathological Society of Japan 49, 689-697.

Gritzal, M. \& BRown, R. D. (1979). The cellulase system of Trichoderma: relationship between purified extracellular enzymes from induced cellulose grown cells. Advances in Chemistry Series 181, 237260.

KUBICEK, C. P. (1987). Involvement of a conidial endoglucanase and a plasma-membrane-bound $\beta$ glucosidase in the induction of endoglucanase synthesis by cellulose in Trichoderma reesei. Journal of General Microbiology 133, 1481-1487.

Lowe, S. E., Theodorou, M. K. \& Trinci, A. P. J. (1987). Cellulases and xylanases of an anaerobic rumen fungus grown on wheat straw holocellulose, cellulose and xylan. Applied and Environmental Microbiology 53, 1216-1223.

LynCh, J. M., Slater, J. H., Bennett, H. A. \& HARPER, S. H. T. (1981). Cellulase activities of some aerobic micro-organisms isolated from soil. Journal of General Microbiology 127, 231-236.

Mandels, M. \& REESE, E. T. (1960). Induction of cellulase in fungi by cellobiose. Journal of Bacteriology 79, 816-826.

Mandels, M., Parrish, F. W. \& Reese, E. T. (1962). Sophorose as an inducer of cellulase in Trichoderma viride. Journal of Bacteriology 83, 400-408.

Merivouri, H., Siegler, K. M., Sands, J. A. \& MONTENCOURT, B. S. (1984). Regulation of cellulase biosynthesis and secretion in fungi. Biochemical Society Transactions 13, 411-414.

Nanda, M., Bisaria, V. S. \& Ghose, T. K. (1986). Effect of L-sorbose on cellulase activity in Trichoderma reesei QM9414. Journal of General Microbiology 132, 3201-3207.

NioH, T. \& Mizushima, S. (1974). Effect of validamycin A on the growth and morphology of Pellicularia sasaki. Journal of General and Applied Microbiology 20, 373-383.

OKaDA, G. \& Nisizawa, K. (1979). Enzymatic studies on a cellulase system of Trichoderma viride. III. Transglycosylation properties of two cellulase components of random type. Journal of Biochemistry 78, 297-306.
RIDE, J. P. \& DR YSDALE, R. B. (1972). A rapid method for the chemical estimation of filamentous fungi in plant tissue. Physiological Plant Pathology 2, 7-15.

Robson, G. D., Kuhn, P. J. \& Trinci, A. P. J. (1988). Effects of validamycin A on the morphology, growth and sporulation of Rhizoctonia cerealis, Fusarium culmorum and other fungi. Journal of General Microbiology 134, 3187-3194.

Robson, G. D., KuHn, P. J. \& Trinci, A. P. J. (1989). Effect of validamycin $A$ on the inositol content and branching of Rhizoctonia cerealis and other fungi. Journal of General Microbiology 135, 739-750.

SAHOO, D. K., Mishra, S. \& BisARIA, V. S. (1986). Influence of L-sorbose on growth and enzyme synthesis of Trichoderma reesei C-5. Journal of General Microbiology 132, 2761-2766.

STEINBERG, D. \& MANDELS, G. R. (1979). Induction of cellulytic enzymes in Trichoderma reesei by sophorose. Journal of Bacteriology 139, 761-769.

Trinci, A. P. J. (1985). Effect of validamycin A and Lsorbose on the growth and morphology of Rhizoctonia cerealis and Rhizoctonia solani. Experimental Mycology 9, 20-27.

UyedA, M., IKeda, A., Machimoto, T. \& Shibata, M. (1985). Effect of validamycin on production of some enzymes in Rhizoctonia solani. Agricultural and Biological Chemistry 49, 3485-3491.

Uyeda, M., IKeda, A., Ogata, T. \& Shibata, M. (1986). Effect of validamycin A on $\beta$-D-glucan degrading enzymes from Rhizoctonia solani. Agricultural and Biological Chemistry 50, 1860-1885.

VAHERI, M. P., Leisola, M. \& KaupinNen, V. (1979). Transglycosylation products of the cellulase system of Trichoderma reesei. Biotechnology Letters 1, 41-46.

VoGEL, H. J. (1956). A convenient growth medium for Neurospora (Medium N). Microbial Genetics Bulletin 13, 42-44.

WAKAe, O. \& MATSUURA, K. (1975). Characteristics of validamycin as a fungicide for Rhizoctonia disease control. Review of Plant Protection Research 8, 81-92.

Willick, G. E., Morosoll, R., Seligy, V. L., YAGUCHI, M. \& DESROCHERS, M. (1984). Extracellular proteins secreted by the basidiomycete Schizophyllum commune in response to various carbon sources. Journal of Bacteriology 159, 294-299. 